Aureliano-Silva, L. (2017). O efeito da marca de eventos musicais com diferentes níveis de congruência do artistacelebridade. Consumer Behavior Review, 1(1) 1-10.

ISSN: 2526-7884

Editor: Prof. Dr. Marconi Freitas da Costa Email da revista: cbr@ufpe.br
Avaliação: Double blind review

Recebido: 23 de novembro de 2016

Aceito: 30 de março de 2017

\title{
O Efeito da Marca de Eventos Musicais com Diferentes Níveis de Congruência do Artista- Celebridade
}

\author{
Leonardo Aureliano-Silva
}

Leonardo Aureliano-Silva é Professor do Mestrado Profissional Gestão em Alimentos e Bebidas, Universidade Anhembi Morumbi - UAM, E-mail: leonardoaureliano@outlook.com._0 autor agracedece aos avaliadores pelos comentários para melhoria do artigo.

\begin{abstract}
Resumo
O principal objetivo desse estudo foi analisar o efeito da marca do evento no comportamento do consumidor de eventos musicais. Para isso foi realizado um experimento com 217 indivíduos, e constatado que uma marca reconhecida aumenta a intenção de compra do ingresso e a percepção de qualidade do evento. A marca reconhecida foi mais bem avaliada quando contou com artistacelebridade de alta congruência com o evento, tanto para intenção de compra do ingresso como percepção de qualidade. A marca não reconhecida foi mais bem avaliada apenas em relação à percepção de qualidade do evento quando contou com artista-celebridade de alta congruência com o evento.

Palavras-chave: Marca; evento musical; artista; celebridade; congruência.
\end{abstract}

Esta obra está licenciado com uma Licença Creative Commons Atribuição 4.0 Internacional.

\section{INTRODUÇÃO}

No Brasil, o gasto anual per capita com entretenimento em dólares foi de US\$152, em 2005, para US\$359, em 2012. 0 mercado de entretenimento no ano de 2013 movimentou US\$ 4,4 bilhões com a venda de 60 milhões de ingressos (Ranking Billborad, 2013). Esses números representam a importância deste setor para a economia do país, e a necessidade de entender o comportamento do consumidor deste tipo de evento. A importância em estudar nomes de eventos musicais, enquanto marcas de entretenimento se sustentam do ponto de vista econômico, por gerar empregos e renda, e 
também social, por viabilizar o acesso à cultura e lazer à população.

Outro aspecto a se destacar é que, em função da alta competitividade deste setor, algumas empresas investem em formas alternativas para atingir o seu target. Uma dessas formas é conhecida como brand experience, cujo objetivo é proporcionar experiência para o consumidor por meio da marca em eventos de entretenimento, por exemplo, eventos musicais. A marca de cerveja Skol, continuamente promove o evento musical Skol Beats que leva o seu nome, e tem como foco buscar maior aproximação entre seu público-alvo e a marca. 0 evento recebe um público jovem, característica essa, que reflete o target da marca Skol.

Rock in Rio é outro evento famoso que teve sua origem no Brasil em 1985 e tem contado com a presença de bandas nacionais e internacionais (Carneiro, 2011). Esse evento atrai consumidores com uma característica mais específica; são amantes do Rock in Roll. Especificamente no evento Rock in Rio, alguns artistas-celebridades de outros gêneros musicais tem participado e gerado insatisfação por parte dos consumidores que fazem parte da tribo Rock in Roll. Um dos maiores desafios dos gestores do evento é equilibrar a participação de bandas de Rock in Roll como Metalica, Iron Maiden e Rolling Stones e cantores de outros gêneros musicais.

Nesse estudo, argumenta-se que, alinhar a participação do artista-celebridade com o gênero musical do evento é fundamental para influenciar positivamente o comportamento do consumidor. Cabe ressaltar que o nome do evento musical ao longo do tempo, torna-se uma marca com uma personalidade específica, para um público específico. Assim, a participação de artistas-celebridades que não possuem adequação com o gênero musical do evento, pode prejudicar a imagem da marca (Venuti, 2009).

Estudos no campo do marketing têm mostrado que a utilização de celebridades em estratégias de promoção pode ser favorável quando há congruência entre a celebridade e o produto endossado (Kim \& Na, 2007; Gurel \& Kahle, 2010). Porém, em situações que a celebridade não tem perfil com o produto que está recomendado, pode gerar incerteza na avaliação do consumidor (Kim \& Na, 2007; Mcnamara, 2009; Silva et al., 2012).

A mesma lógica se aplica na dinâmica entre artista-celebridade e o gênero do evento musical. Parte da literatura deixa lacuna em que condições a não adequação da celebridade, conhecida como incongruência, ao endossar um produto, pode afetar positiva ou negativamente a avaliação do consumidor, inclusive, tratandose de eventos de entretenimentos, que é o foco deste estudo.

Diferentemente de estudos anteriores (Till \& Shimp, 1998; Sliburyte, 2009; Cortini, Vicenti \& Zuffo, 2010) e a fim de contribuir para uma melhor compreensão teórica e substantiva desse fenômeno, propõe-se a seguinte pergunta de pesquisa: Qual o efeito da marca do evento musical na intenção de compra do ingresso e percepção de qualidade do evento? 0 principal objetivo desse estudo foi analisar o efeito da marca do evento no comportamento do consumidor de eventos musicais. Do ponto de vista acadêmico, compreender a avaliação deste consumidor contribui para ampliar a teoria do comportamento do consumidor, aplicada na avaliação de eventos de entretenimento, e também auxiliar gerentes de eventos de entretenimento na escolha e contratação de artistas-celebridades.

Após essa breve introdução, apresenta-se estudos teórico-empíricos e as hipóteses a serem testadas, na sequencia o método e os resultados. Por fim, a discussão geral e sugestão de pesquisas futuras.

\section{ELABORAÇÃO DAS HIPÓTESES}

Esta seção apresenta revisão de pesquisas teórico-empíricas e as hipóteses que serão testadas nos experimentos seguintes.

\section{Marcas}

Marca tem sido evidenciada em estudos acadêmicos como o principal atributo que o consumidor considera para avaliação de um produto e decisão de compra (Šeimienè \& Ankovič, 2014; Hernandez, 2013; Aaker, 1997). Além de servir para identificar o fabricante do produto, também diferencia e agrega valor (Caputo, Macedo \& Nogueira, 2008; Gonçalves Filho, Souki \& Gonçalves, 2009). Keller, Heckler e Houston (1998) afirmaram que a marca é decisiva para o sucesso do produto por 
comunicar suas qualidades. Silva et al. (2012) identificaram que marcas reconhecidas são bem avaliadas independentemente de serem recomendadas por uma celebridade pois possuem a confiança do consumidor. Lopes et al. (2013) constataram que experts são mais sensíveis a presença da marca para julgamento de um produto pois refletem a qualidade do produto. Esses estudos convergem para o entendimento de que, a principal pista usada pelo consumidor para decidir sua compra e avaliar a qualidade do produto é a marca que ele possui.

Da mesma maneira que o consumidor utilizase da marca para avaliação de produtos de outras categorias (Joji, 2011), sugere-se que o consumidor ancora-se no nome do evento (marca) para manifestar sua intenção de compra e percepção de qualidade do evento musical (Wang \& Tsai, 2014). Como apresentado, marca é o principal atributo que o consumidor utiliza para julgar o produto e simplificar o seu processo de compra, além de reduzir riscos relacionados à qualidade (Gonçalves Filho, Souki \& Gonçalves, 2009).

Análogo ao processo de avaliação de marcas de produtos de outras categorias (Aaker, 1997; Hernandez et al., 2011), e ancorado em estudos sobre essa temática, sugere-se que o nome de um evento, quando visto como uma marca reconhecida, leva o consumidor a aumentar a intenção de compra do ingresso e a perceber maior qualidade no evento quando comparada a uma marca não reconhecida ou de menor expressão. Para analisar e operacionalizar essa argumentação propõe-se as hipóteses a seguir, sendo: H1 - a marca reconhecida de evento [Rock In Rio] será mais bem avaliada comparada a marca não reconhecida [Rock Festival] sobre a intenção de compra do ingresso; H2 - a marca reconhecida de evento [Rock in Rio] será mais bem avaliada comparada a marca não reconhecida [Rock Festival] sobre a percepção de qualidade do evento.

\section{Artista-Celebridade}

Celebridades são indivíduos que estão em evidência na mídia e são admiradas por determinados grupos (Keel \& Nataraajan, 2011), seja pela beleza física, ou por se desempenharem de forma excepcional em alguma área de atuação (Kahle \& Homer, 1985;
Baker \& Gilbert, 1997; Kelting \& Rice, 2013). Por exemplo, um ator pode se tornar uma celebridade por desempenhar de forma excepcional um determinado personagem e passar a ter alta exposição na mídia (Friedman \& Friedman, 1979; Banytè, Stonkienè, \& Piligrimienè, 2011). Características como experiência, credibilidade, beleza física e carisma também são qualidades consideradas na contratação de uma celebridade para endossamento (Sliburyte, 2009; Till \& Shimp, 1998; Baker \& Gilbert, 1997).

Sabe-se que muitos fãs acompanham a vida de suas celebridades prediletas. A relação é enfatizada pela divulgação de detalhes dos bastidores de gravação, notícias pessoais na mídia, ou a compra de revistas populares que tratam do assunto (Meyers, 2009). Alguns adotam o mesmo corte de cabelo, fazem tatuagens, e outros vão mais longe, e fazem cirurgias plásticas para parecerem com a sua celebridade predileta. Da mesma forma, quando os consumidores veem suas celebridades favoritas usando determinados produtos, estes rapidamente criam meios de também adquirilos (Erdogan, 2010; Hung, 2014).

Ao apresentar uma celebridade e produto simultaneamente, o consumidor faz associações entre as duas figuras (Misra \& Beatty, 1990; Chen et al., 2013), possibilitando a transferência de significados, inclusive quando há congruência entre celebridade e produto endossado (Fleck, Korchia, \& Roy, 2012). Congruência é vista com um conjunto de características que torna a celebridade adequada para recomendar um produto (Kim \& $\mathrm{Na}, 2007)$. Esse fenômeno já foi discutido e evidenciado novamente por Till e Shimp (1998), sobre endossamento de marcas. A congruência faz com que o consumidor perceba similaridade entre a celebridade e o produto (Misra \& Beatty, 1990).

A lógica que perfaz esse fenômeno é que, quanto mais bem vista for à celebridade, e maior for a congruência com o produto, mais credibilidade ela dará ao produto que estiver endossando; logo, os consumidores serão influenciados pela celebridade e estarão mais propensos a avaliar positivamente o produto e incluí-lo em suas decisões de compra.

De fato, uma celebridade tem condições de influenciar positivo, ou negativamente a avaliação do consumidor em relação ao produto 
que está endossando (Chen et al., 2012), e, evidências empíricas têm indicado que a adequação do perfil da celebridade ao tipo de produto que está recomendando, é fundamental para que o endosso se potencialize e influencie positivamente o comportamento do consumidor (Lee \& Park, 2014). Inclusive, quando se tratar de marcas não reconhecidas pelo mercado (Silva et. al., 2012).

Em estudo realizado por Silva et al., (2012) identificou-se que o endossamento por celebridade pode não ser uma boa estratégia quando se trata de marca reconhecida pelo mercado. Assim afirma-se que: H3 - a marca reconhecida [Rock In Rio] independerá da congruência da celebridade para sua avaliação quanto à intenção de compra do ingresso e H4 a marca reconhecida [Rock In Rio] independerá da congruência da celebridade para sua avaliação quanto percepção de qualidade do evento musical.

Porém, quando o endossamento é feito para marcas não reconhecidas, ou de menor expressão, o endossamento por celebridade de alta congruência com a categoria do produto tem melhorado as avaliações do consumidor (Tse, Sejung \& Kineta, 2010; Zwilling \& Fruchter, 2013). Assim propõe-se: H5 - a marca não reconhecida [Rock Festival] será mais bem avaliada sobre a intenção de compra do ingresso quando contar com o endosso por celebridade de alta congruência [versus baixa congruência] com o gênero do evento musical e em H6 - a marca não reconhecida de evento musical [Rock Festival] será mais bem avaliada sobre a percepção de qualidade do evento quando contar com o endosso por celebridade de alta congruência [versus. baixa congruência] com o gênero do evento musical.

\section{DESENHO EXPERIMENTAL}

$O$ objetivo do experimento será analisar o efeito da marca do evento musical e da congruência do artista-celebridade sobre a avaliação do consumidor. Para isso utilizou-se um desenho fatorial $2 \times 2$ - Eventos [Marcas: reconhecida vs. não reconhecida] $\mathrm{x} 2$ Celebridades [Congruências: alta vs. baixa].

\section{Desenvolvimento dos estímulos}

Primeiramente, procedeu-se a escolha dos estímulos a serem utilizados no experimento.
Para identificar o nome de marca reconhecida de evento musical, recorreu-se a um grupo de alunos $(n=5)$ do curso de administração que informaram por unanimidade, ser Rock In Rio, uma marca de evento musical reconhecida. Para definir uma marca não reconhecida de evento, recorreu-se a internet para identificar o nome de algum evento. Na sequência, a marca não reconhecida foi submetida à avaliação de um grupo de alunos $(n=7)$ que informaram não ser uma marca de evento musical reconhecida, inclusive por não conhecerem o evento. Ambas as marcas foram avaliação por meio de uma escala Likert de 7 pontos, sendo que a marca reconhecida foi mais bem avaliada comparada a marca não reconhecida $\left(\right.$ Marca $_{\text {RockinRio }}=5,32$ vs. Marca $\left._{\text {RockFestival }}=2,36 ; \mathrm{p}<0,01\right)$. Assim, concluiuse como a marca reconhecida de evento [Rock in Rio] e a marca não reconhecida de evento [Rock Festival].

A etapa seguinte foi à definição de um artista-celebridade considerando a sua congruência com o evento musical. Os artistas também foram definidos pelos pesquisadores. Escolheu-se os artistas-celebridades Mick Jagger e Claudia Leite por serem artistas que têm participado do Rock in Rio. Ambos os artistas foram apresentados a um grupo de alunos $(n=10)$ para que julgasse, qual das celebridades teriam maior congruência [adequação] com o evento de Rock. Concluiu-se, com essa etapa, Mick Jagger [alta congruência] e Claudia Leite [baixa congruência] - (Ver anexo).

\section{Amostra e procedimento de controle}

A amostra foi composta por estudantes do curso de Administração de uma universidade da cidade de São Paulo. Esses estudantes em sua maioria trabalham durante o dia e estudam durante o período noturno. São independentes financeiramente e tomam suas próprias decisões de compra. A coleta de dados ocorreu durante as aulas, no período noturno.

\section{Design geral do instrumento de coleta de dados}

0 primeiro passo foi pré-testar o instrumento de coleta de dados. Utilizou-se uma amostra composta por $(\mathrm{n}=15)$ estudantes universitários. 0 pré-teste foi conduzido pelos autores deste trabalho e teve como objetivo 
possibilitar o ajuste das afirmativas e eventuais correções.

O questionário utilizado para coleta dos dados foi composto de três partes. A primeira parte apresentava a imagem de um artistacelebridade confirmando sua presença no evento. A segunda parte do questionário foi composta por afirmativas destinadas a avaliar a Intenção de compra do ingresso < Se essa celebridade for se apresentar eu comprarei o ingresso; Comprarei o ingresso assim que estiver disponível; Eu iria a esse evento, mesmo que essa celebridade não fosse participar> e Percepção de qualidade do evento $<1$ - Com a participação dessa celebridade o evento será de alta qualidade; 2 - Com a presença dessa celebridade, a qualidade do evento será excelente ; 3 - Gostaria de ir a esse evento que será de muita qualidade> adaptadas de (Aureliano-Silva et al., 2015). Utilizou-se uma escala de 7 pontos do tipo Likert (1 discordo completamente e 7 concordo completamente), para as afirmativas de Intenção de compra; Percepção de qualidade; checagem da manipulação da marca < Em minha opinião, (marca do evento) é uma marca reconhecida de evento>; congruência da celebridade < Essa celebridade tem a "cara" do evento $>$ e solicitouse também o nome da celebridade. Por fim, solicitou-se os dados categóricos dos respondentes, como gênero, idade e renda para caracterização da amostra.

\section{Plano de análise dos dados}

Para análise dos dados foi utilizada técnicas de análise descritiva; média; desvio-padrão; limites mínimo e máximo com intervalo de confiança (IC) de 95\% para a diferença média da população estimada e análise de variância ANOVA, com alfa de [ $\alpha=5 \%]$ e probabilidade; $\mathrm{p}<0,05$, descrição do tamanho do efeito por meio do índice de Cohen $(d)$ para os testes $t$ de student e ômega quadrado $(\omega)$ para análises de variância.

\section{Resultados do experimento}

A amostra deste experimento foi composta por 217 avaliadores, sendo que 109 (51\%) indivíduos avaliaram a propaganda com a marca Rock In Rio, e outros 108 (49 \%) avaliaram a marca Rock Festival. A amostra segundo o gênero do avaliador foi de 75 (35\%) homens e 142 (65\%) mulheres. A idade média dos avaliadores é de 26 anos ( $\sigma=5$ anos), sendo a renda média mensal de $\mathrm{R} \$ 1.748 .59$.

Após a caracterização da amostra, realizouse a checagem da manipulação do reconhecimento da marca do evento (RockInRio $_{\text {Média }}=5,91 ; \quad \mathrm{dp}=1,43$; RockFestival $_{\text {Média }}=4,39 ; d p=1,83, t(215)=6,801$, $\mathrm{p}<0,001$ ) com diferença média entre as condições de $(\mathrm{m}=1,52 ; d=0,93 ; \mathrm{IC}=-1,96 ;-1,08)$. Como se esperava, a marca Rock In Rio foi em média mais bem avaliada comparada à marca Rock Festival, confirmando esta última, como marca de evento musical não reconhecida.

Também foi realizada a checagem da manipulação da congruência do artista com o evento musical. Para isso, utilizou-se a seguinte afirmativa (Essa celebridade tem perfil com o evento musical sendo (1 - Discordo totalmente e 7 Concordo totalmente). Os resultados indicaram $\quad$ (MickJagger $_{\text {Média }}=6,02 ; \quad d p=1,21$; ClaudiaLeite $_{\text {Média }}=2,15 ; d p=1,53, t(128)=13,779$, $\mathrm{p}<0,001$; com diferença média entre as condições de $(\mathrm{m}=2,82 ; d=2,82 ; \mathrm{IC}=3,49 ; 4,23)$. Portanto, Mick Jagger foi classificado como artista de alta congruência com o evento musical, e a cantora Claudia Leite como de baixa congruência.

A confiabilidade interna dos itens que formaram as variáveis dependentes foi identificada por meio do coeficiente Alfa de Cronbach, sendo 3 itens $(\alpha=0,672)$ para Intenção de compra, e 3 itens $(\alpha=0,795)$ Percepção de qualidade. Esses itens foram considerados satisfatórios para a finalidade deste estudo (Hair et al, 2005).

$\mathrm{Na}$ sequência procedeu-se a análise dos efeitos principais da marca na Intenção de compra e Percepção de qualidade do evento musical. Identificou-se efeito principal para a marca do evento musical em relação à Intenção de compra $(F(1,215)=8,249 ; p<0,01 ; \omega=0,18$ e para Percepção de qualidade $(\mathrm{F}(1,128)=5,509$; $\mathrm{p}<0,05) ; \omega=0,07)$.

Foi identificado também efeito principal da celebridade Intenção de compra $(\mathrm{F}(1,215)=$ 4,404; p<0,05; $\omega=0,12$ e para Percepção de qualidade $(F(1,215)=5,472 ; p<0,01) ; \omega=0,45$. Não foi identificado efeito de interação entre marca e celebridade $(F(1,215)=p>0,10)$ para nenhuma das variáveis dependentes. 
Os resultados indicaram que a marca reconhecida foi mais bem avaliada comparada a marca não reconhecida quanto a intenção de compra do ingresso (RockinRio Média $=3,92$; $\mathrm{dp}=1,38$ e RockFestival $_{\text {Média }=3,43 ; \quad d p=1,26 ;}$ $t(215)=2,723 ; \mathrm{p}<0,05) ;$ com diferença média entre as condições de $(\mathrm{m}=0,49 ; d=0,37$; IC=0,84; -0,13) e para percepção de qualidade (RockinRio $_{\text {Média }}=4,26 ; \quad \mathrm{dp}=1,73$ e RockFestival $_{\text {Média }} 3,63 ; \quad \mathrm{dp}=1,57 ; \quad \mathrm{t}(215)=$ 1,444; $<0,05)$; com diferença média entre as condições de $(\mathrm{m}=0,63 ; d=0,20 ; \mathrm{IC}=-0,76 ;-0,11)$.

Os resultados da avaliação da marca mostraram que a intenção de compra do ingresso para o evento musical Rock in Rio é maior comparada a do Rock Festival. A percepção de qualidade do evento Rock in Rio também se mostrou superior em relação à marca Rock Festival. Esses resultados evidenciam que o consumidor de eventos musicais se ancora na marca para avaliação do evento, sendo esse processo, semelhante à decisão de compra de produtos de outras categorias.

Dando seqüência ao estudo, analisou-se o efeito da marca do evento com diferentes níveis de congruência. Em relação à intenção de compra do ingresso da marca reconhecida (Rock in Rio) com diferentes níveis de congruência (MickJagger Altacongruência $=3,87$; $\mathrm{dp}=1,42$ e $\quad$ ClaudiaLeite Baixacongruência $=3,49_{\text {; }}$ $\mathrm{dp}=1,24 ; t(215)=2,099 ; \mathrm{p}<0,05)$; com diferença média entre as condições de $(\mathrm{m}=0,38 ; d=0,28$; $\mathrm{IC}=, 023$; 0,73) e para percepção de qualidade (MickJagger $_{\text {Altacongruência }}=4,88 ; \mathrm{dp}=1,41 \mathrm{e}=$

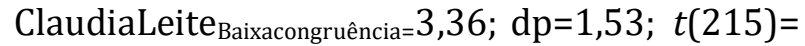
7,581; $\mathrm{p}<0,05$; com diferença média entre as condições de $(\mathrm{m}=1,52 ; d=1,03$; IC=1,12; 1,92).

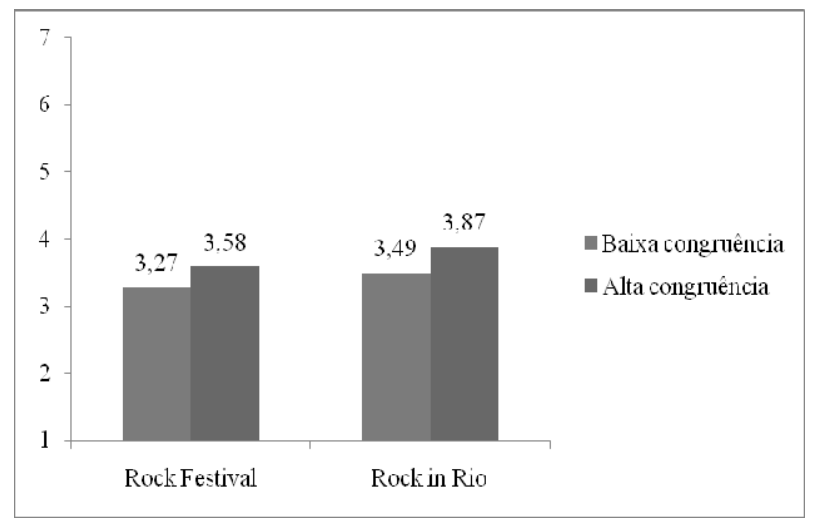

Figura 1. Intenção de compra
Verificou-se que a intenção de compra do ingresso da marca reconhecida de evento musical foi maior quando contou com o artistacelebridade de alta congruência. Na seqüência procedeu-se a análise da avaliação da marca não reconhecida. Os resultados são sumarizados na Figura 1 e 2, sendo uma representação gráfica dos resultados.

A avaliação da marca não reconhecida (Rock Festival) com diferentes níveis de congruências foram (MickJagger Alta_congruência $=3,58 ; \mathrm{dp}=1,37 \mathrm{e}=$

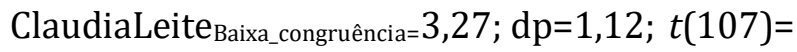
1,272; $\mathrm{p}>0,10$; com diferença média entre as condições de $(\mathrm{m}=0,31 ; d=0,12 ; \mathrm{IC}=-, 17 ; 0,78)$ para intenção de compra, e, (MickJagger $_{\text {Alta_congruência }}=4,56 ; \mathrm{dp}=1,31$ e =

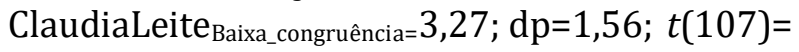
4,692;p<0,01); com diferença média entre as condições de $(\mathrm{m}=1,29 ; d=0,45 ; \mathrm{IC}=0,74 ; 1,84)$ para percepção de qualidade.

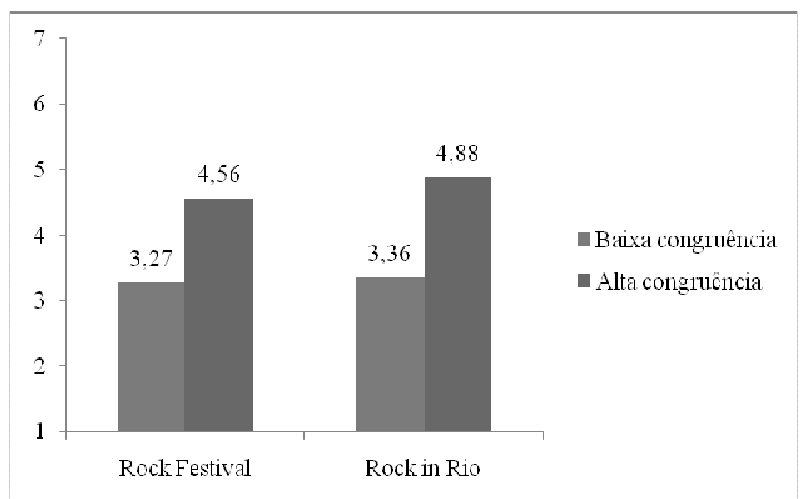

Figura 2. Percepção da qualidade

A avaliação das marcas de evento reconhecida e não reconhecida com alta congruência foi de (Rock in Rio Alta_congruência $=4,20$; $\mathrm{dp}=1,41$ e Rock Festival Alta_congruência $_{1,3,58}$ e $\mathrm{dp}=1,37 ; t(103)=2,289 ; \mathrm{p}<0,05)$ para intenção de compra, com diferença média entre as condições de $(\mathrm{m}=0,62 ; d=0,45 ; \mathrm{IC}=-1,16 ;-0,08)$. Para percepção de qualidade do evento (Rock in

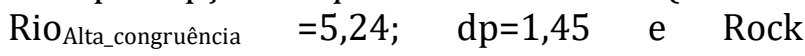
Festival $_{\text {Alta_congruência }}=4,56$ e $\mathrm{dp}=1,31 ; t(103)=$ 2,526;p<0,05; com diferença média entre as condições de $(\mathrm{m}=0,62 ; d=0,50 ; \mathrm{IC}=-1,16 ;-0,08)$.

E por fim, a avaliação das marcas de evento reconhecida e não reconhecida com baixa congruência foi (Rock in Rio Baixacongruência $=3,68$; $\mathrm{dp}=1,33$ e Rock Festival Baixacongruência $=3,27$ e $\mathrm{dp}=1,12 ; t(110)=1,763 ; \mathrm{p}=\mathrm{n} . \mathrm{s} ;$ com diferença média entre as condições de $(\mathrm{m}=0,41 ; d=0,34$; 
IC=-,87;0,51) para intenção de compra, e, (Rock

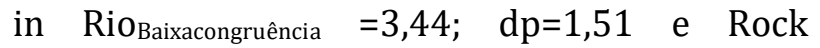
Festival $_{\text {Baixacongruência }}=3,27$ e $d p=1,56 ; t(110)=$ 0,584; $>0,10$; com diferença média entre as condições de $(\mathrm{m}=0,17 ; \quad d=0,11 ; \quad \mathrm{IC}=$ 0,$74 ; 0,40$ ) para percepção de qualidade.

Observou-se que, a marca não reconhecida de evento musical foi mais bem avaliada apenas em relação à Percepção de qualidade. A participação de artistas-celebridades com baixa congruência não contribuiu para uma melhor avaliação das marcas reconhecida e não reconhecida.

\section{Discussão dos resultados}

Neste estudo analisou-se o efeito da marca de um evento musical na intenção de compra do ingresso e percepção de qualidade. Constatouse que uma marca reconhecida de evento é mais bem avaliada comparada a uma marca não reconhecida. Quanto à intenção de compra do ingresso, verificou-se que a marca Rock in Rio foi mais bem avaliada com a participação do artista-celebridade de alta congruência (Mick Jagger) no evento, comparada com a artistacelebridade de baixa congruência (Claudia Leite). Não se observou mudança na avaliação da marca não reconhecida de evento, Rock Festival, tanto com artista-celebridade de alta como de baixa congruência. Porém, tanto as marcas Rock in Rio como Rock Festival foram avaliadas da mesma maneira, quando o artistacelebridade era de baixa congruência.

Em relação à Percepção de qualidade, o evento Rock in Rio foi mais bem avaliado com a participação do artista-celebridade de alta congruência (Mick Jagger) comparado a Cláudia Leite (baixa congruência). 0 evento Rock Festival também foi mais bem avaliado quando contou com a participação da celebridade de alta congruência (Mick Jagger).

Em resumo, ambos os eventos musicais foram mais bem avaliados quando contaram com a participação do artista-celebridade de alta congruência comparada ao de baixa congruência.

Tabela 1

Resumo das Hipóteses

\begin{tabular}{|c|c|}
\hline Hipóteses & Resultados \\
\hline $\begin{array}{l}\text { H1 - a marca reconhecida de evento [Rock In Rio] será mais bem avaliada comparada a } \\
\text { marca não reconhecida [Rock Festival] sobre a intenção de compra do ingresso; }\end{array}$ & Suportada \\
\hline $\begin{array}{l}\text { H2 - a marca reconhecida de evento [Rock in Rio] será mais bem avaliada comparada a } \\
\text { marca não reconhecida [Rock Festival] sobre a percepção de qualidade do evento; }\end{array}$ & Suportada \\
\hline $\begin{array}{l}\text { H3 - a marca reconhecida [Rock In Rio] independerá da congruência da celebridade para sua } \\
\text { avaliação quanto à intenção de compra do ingresso; }\end{array}$ & Não suportada \\
\hline $\begin{array}{l}\text { H4 - a marca reconhecida [Rock In Rio] independerá da congruência da celebridade para sua } \\
\text { avaliação sobre a percepção de qualidade do evento musical; }\end{array}$ & Não suportada \\
\hline $\begin{array}{l}\text { H5 - a marca não reconhecida [Rock Festival] será mais bem avaliada sobre a intenção de } \\
\text { compra do ingresso quando contar com o endosso por celebridade de alta congruência } \\
\text { [versus baixa congruência] com o gênero do evento musical; }\end{array}$ & Não suportada \\
\hline $\begin{array}{l}\text { H6 - a marca não reconhecida de evento musical [Rock Festival] será mais bem avaliada } \\
\text { sobre a percepção de qualidade do evento quando contar com o endosso por celebridade de } \\
\text { alta congruência [versus. baixa congruência] com o gênero do evento musical. }\end{array}$ & Suportada \\
\hline
\end{tabular}

Nota. Fonte: Elaborado pelo autor.

\section{CONCLUSÃO}

O escopo desta seção é promover a discussão geral dos resultados encontrados por meio da pesquisa empírica e apresentar os seus limites, além de sugerir pesquisas futuras com ênfase no prosseguimento dessa linha temática.

Observou-se por meio do experimento realizado que a avaliação do consumidor sobre eventos musicais é semelhante às de outras categorias de produtos, ou seja, a marca é o ponto de referência para o consumidor fazer seu julgamento.

Acreditava-se que uma marca reconhecida de evento, não fosse mais bem avaliada quando um artista-celebridade de alta congruência com o gênero do evento musical confirmasse a sua presença, já que a marca por si só, é o atributo principal para avaliação do consumidor. Entretanto, a marca reconhecida de evento (Rock in Rio) foi mais bem avaliada, tanto sobre a intenção de compra do ingresso, como a 
percepção de qualidade do evento com a confirmação do artista-celebridade Mick Jagger. Isto sugere que, consumidores de eventos musicais avaliam serviços diferentemente de produtos, e que, a congruência entre o gênero do evento musical e o artista-celebridade deve ser considerada.

Em relação à marca não reconhecida de evento, o fato de ser confirmada a presença de um artista-celebridade de alta congruência não influenciou a intenção de compra do ingresso, mas aumentou a percepção de qualidade do evento musical. Esse achado é convergente com o endosso de celebridade para marcas não reconhecidas pelo mercado, em que, num primeiro momento, a ideia é fixar atributos positivos entre marca e celebridade e assim atrair o consumidor para um primeiro contato com o produto.

Do ponto de vista acadêmico, esse estudo contribui para ampliar o conhecimento sobre as teorias de marca, endossamento por celebridade e comportamento do consumidor. Preenche uma lacuna sobre a compreensão da participação de celebridades com diferentes níveis de congruências em eventos musicais e o efeito da congruência sobre a avaliação do consumidor. Do ponto de vista mercadológico, esse estudo contribui para uma melhor análise por parte de gestores de eventos musicais na decisão de contratação de artistas-celebridades. Gestores e promotores de eventos musicais poderão observar que, criar uma personalidade de marca alinhada ao target do evento, deve estar de acordo com gênero e a congruência musical do artista.

\section{Recomendações para futuras pesquisas}

Pesquisas futuras poderão investigar se o nível de envolvimento do consumidor com a celebridade é uma variável que influencia a avaliação da marca do evento. Também poderão avaliar o nível de experiência do consumidor com a marca do evento, e se, esse aspecto é um antecedente de recomendação para outros consumidores, ou mesmo, se fortalece a intenção de compra de outros produtos de outras categorias vinculados à marca do evento, por exemplo, o automóvel Gol versão Rock in Rio da fabricante Volkswagem.

Pode-se analisar também em estudos futuros se a admiração ou a rejeição pelo artista- celebridade que pode participar do evento, dentro outros, seja um fator que impacta na avaliação do evento.

Como recomendação de pesquisas futuras, pode-se investigar o nível de envolvimento com eventos musicais e seus artistas-celebridades na formação do self do consumidor dentre outros eventos como Skol Beats e LollaPalooza no Brasil.

\section{REFERÊNCIAS}

Aaker, J. L. (1997). Dimensions of brand personality. Journal of Marketing Research, 34(3), 347-356.

Azevedo, C. (2007). Subgêneros de metal no Rio de Janeiro a partir da década de 1980. Cadernos do Colóquio, 7(1).

Aureliano-Silva, L. (2015). Efeito da marca em propagandas com diferentes frames promocionais: Uma pesquisa experimental. Anais do $8^{\circ}$ Congresso Latino Americano de Varejo - CLAV, São Paulo.

Bailey, A. A. (2014). Celebrity endorsement entering the 21st century: A content analysis of print advertising. Proceedings of The Marketing Management Association, 6-7.

Baker, M. J., \& Churchill Jr, G. A. (1997). The impact of physically attractive models on advertising evaluations. Journal of Marketing Research, 538-555.

Banytė, J., Stonkienè, E., \& Piligrimienè, Ž. (2011). Selecting celebrities in advertising: The case of Lithuanian sports celebrity in non sport product advertisement. Economics \& Management, 16(1), 1215-1229.

Caputo, E. S., Macedo, M. D. S., \& Nogueira, H. G. P. (2008). Avaliação de marcas: Uma aplicação ao caso Bombril. Anais do III EMA.

Carneiro, LF. (2011). Rock in Rio: A história do maior festival de música do mundo. São Paulo: Editora Globo, Jan. 1.

Chen, A. C. H., Chang, R. Y. H., Besherat, A., \& Baack, D. W. (2013). Who benefits from multiple brand celebrity endorsements? An experimental investigation. Psychology \& Marketing, 30(10), 850-860.

Chen, C. Y., Lin, Y. H., \& Claussen, C. L. (2012). Celebrity endorsement for sporting events using classical conditioning. International Journal of Sports Marketing and Sponsorship, 13(3), 46-56.

Choi, S. M., \& Rifon, N. J. (2012). It is a match: The impact of congruence between celebrity image and consumer ideal self on 
endorsement effectiveness. Psychology \& Marketing, 29(9), 639-650.

Cortini, M., Vicenti, A., \& Zuffo, R. G. (2010). Celebrity Endorsement and Congruence: An Experimental Study. International Journal of Interdisciplinary Social Sciences, 5(8).

Erdogan, B. Z. (2010). Celebrity endorsement: A literature review. Journal of Marketing Management, 15(4), 291-314.

Fleck, N., Korchia, M., \& Le Roy, I. (2012). Celebrities in advertising: Looking for congruence or likability? Psychology \& Marketing, 29(9), 651-662.

Friedman, H. H., \& Friedman, L. (1979). Endorser effectiveness by product type. Journal of Advertising Research, 19(5), 63-71.

Gonçalves Filho, C., Souki, G. Q., \& Gonçalves, C. A. (2009). Valor das marcas (brand equity) para o consumidor: Desenvolvimento e validação de um instrumento de mensuração no setor automotivo. Revista Eletronica de Ciência Administrativa,8(1), 106.

Gurel, E.; Kahle, L. (2010). Celebrity Endorsements and Advertising Effectiveness: The importance of value congruence. Advances in Consumer Research, 37(3), 807-808.

Hernandez, J. M. C. (2002). Brand trust and online consumer behavior. Advances in Consumer Research Volume 29.

Hernandez, J. M. C., Menck, T. M., Lopez, D. M., Mocellin, L. F. (2011). Extensão de marcas corporativas de serviços: 0 efeito da similaridade percebida da extensão e da qualidade percebida da marca. Revista de Administração Contemporânea, 15(4), 561579.

Hung, K. (2014). Why celebrity sells: A dual entertainment path model of brand endorsement. Journal of Advertising, 43(2), 155-166.

Joji, A. N. (2011). Consumer evaluations of product line brand extension. IUP Journal of Brand Management, 8(1).

Kahle, L. R., \& Homer, P. M. (1985). Physical attractiveness of the celebrity endorser: A social adaptation perspective. Journal of Consumer Research, 11(4), 954-961.

Keel, A., \& Nataraajan, R. (2012). Celebrity endorsements and beyond: New avenues for celebrity branding. Psychology \& Marketing, 29(9), 690-703.

Kelting, K., \& Rice, D. H. (2013). Should we hire David Beckham to endorse our brand? Contextual interference and consumer memory for brands in a celebrity's endorsement portfolio. Psychology \& Marketing, 30(7), 602-613.
Kim, H., \& Park, S. Y. (2011, January). Celebrity endorsement in direct-to-consumer (DTC) pharmaceutical advertising: The effects of celebrity-brand congruence and attributional inferences. Proceedings American Academy of Advertising.

Kim, Y. J., \& Na, J. H. (2007). Effects of celebrity athlete endorsement on attitude towards the product: The role of credibility, attractiveness and the concept of congruence. International Journal of Sports Marketing and Sponsorship, 8(4), 23-33.

Lee, J. G., \& Park, J. (2014). The effects of endorsement strength and celebrity-product match on the evaluation of a sports-related product: the role of product involvement. International Journal of Sports Marketing and Sponsorship, 16(1), 50-69.

Lopes, E. L., da Silva, D., \& da Costa Hernandez, J. M. (2013). O Efeito da Marca na Negligência da Omissão: uma Pesquisa Experimental/Brand Effect on Omission Neglect: an Experimental Research. Revista de Administração Contemporânea, 17(2), 132.

Meyers, E. (2009). Can you handle my truth?: authenticity and the celebrity star image. The Journal of Popular Culture, 42(5), 890-907.

McNamara, K. (2009). Publicising private lives: Celebrities, image control and the reconfiguration of public space. Social \& Cultural Geography, 10(1), 9-23.

Misra, S., \& Beatty, S. E. (1990). Celebrity spokesperson and brand congruence: An assessment of recall and affect.Journal of Business Research, 21(2), 159-173.

Rock in Rio (2015). The World's Legendary Music Festival, Rock in Rio, Heads to U.S. in Business Wire (English). 3.

Silva, L. A. D. (2012). O efeito da marca na avaliação de propagandas endossadas por celebridades. Dissertação de mestrado, Universidade Nove de Julho, São Paulo, SP, Brasil.

Sliburyte, L. (2009). How celebrities can be used in advertising to the best advantage. World Academy of Science, Engineering and Technology, 58(2), 934-939.

Stonkienè, E.; Piligrimienè, Z. (2011). Selecting Celebrities in Advertising: The case of Lithuanian sports celebrity in non sport product advertisement, Economic and Management, 16, 1215-1224.

Till, B. D., \& Shimp, T. A. (1998). Endorsers in advertising: The case of negative celebrity information.Journal of Advertising,27(1), 67-82. 
Tse, C. H.; Sejung Marina, C \& Kineta, H. (2010). Impacts of image congruence in celebrity endorser effects: a need-congruencebehavior model. American Academy of Advertising Conference Proceedings, 48.

Venuti, G. (2009). The impact of sponsor-event fit on music festivals and their brands. Master thesis, University of Amsterdam, Amsterdam, Holanda.
Wang, Y. H., \& Tsai, C. F. (2014). The relationship between brand image and purchase intention: Evidence from award winning mutual funds. The International Journal of Business and Finance Research, 8(2), 27-40.

Zwilling, M., \& Fruchter, G. E. (2013). Matching product attributes to celebrities who reinforce the brand.Journal of Advertising Research, 53(4), 391-410.

\section{The Effect of the Musical Event Brand with Different Levels of Artist-Celebrity Congruence Abstract}

The main objective of this study was to analyze the effect of the event brand on the consumer behavior of musical events. For this, an experiment was carried out with 217 individuals, and it was verified that a recognized brand increases the purchase intention of the ticket and the perception of quality of the event. The recognized brand was better evaluated when it counted on celebrity artist of high congruence with the event, both for purchase intention of the ticket and perception of quality. The unacknowledged brand was best evaluated only in relation to the perceived quality of the event when it featured celebrity artist of high congruence with the event.

Keywords: brand; musical event; artist; celebrity; congruence.

\section{Anexo - Estímulos dos experimentos}
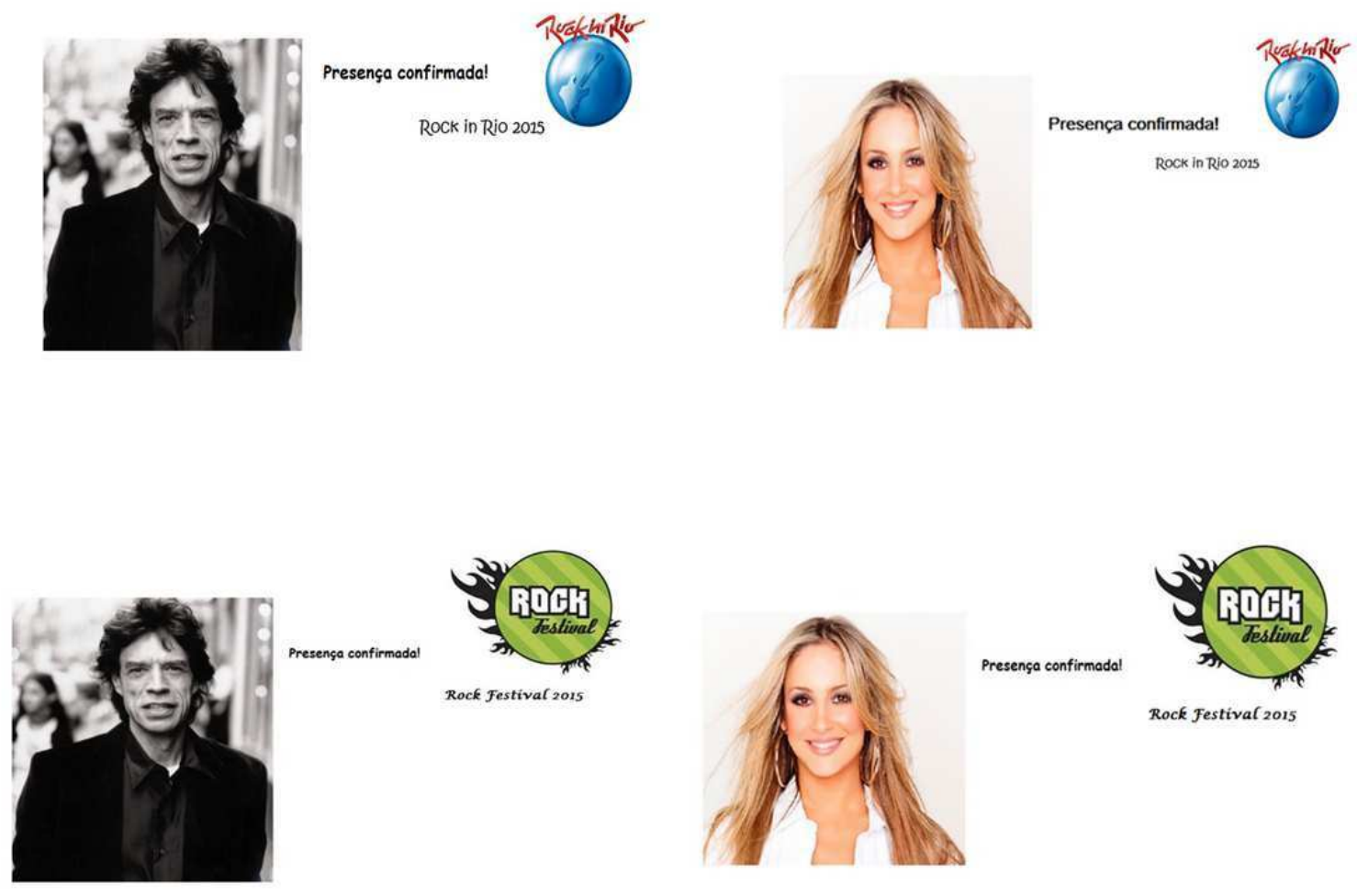